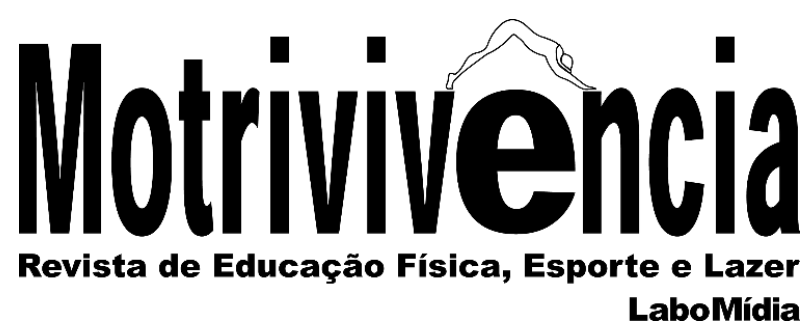

\title{
O circo na educação infantil: vivências e representações artísticas no desenho
}

\section{RESUMO}

O circo sempre manteve estreita relação com o universo infantil, despertando magia, alegria e sonhos. Este estudo analisou representações e apropriações das crianças sobre o circo, a partir de seus próprios desenhos, elaborados numa proposta de atividades circenses. Consistiu num estudo de caso, com 21 crianças de uma instituição de educação infantil, com idade entre 4 a 5 anos. Observou-se que antes da proposta a estrutura externa do circo, a lona, foi o elemento mais representado pelas crianças, sugerindo este fato, que embora algumas crianças nunca tivessem presenciado um espetáculo de circo, conheciam sua estrutura física que em algum momento lhes foi apresentada. Após 12 sessões da proposta pedagógica, a lona do circo deixou de ser o elemento mais representado, surgindo protagonistas, como o malabarista e o mágico. Ficou evidenciado que vivências corporais e o diálogo permitiram ressignificar o circo na educação infantil.

PALAVRAS-CHAVE: Educação infantil; Educação física; Circo; Desenho

\section{Hugo Cavalcante Vasques}

Licenciado em Educação Física Universidade Estadual de Campinas-UNICAMP Departamento de Educação Física e Humanidades Campinas, São Paulo, Brasil hugocvasques@gmail.com 그 http://orcid.org/0000-0003-3386-1897

Giovanna Sayuri Garbelini

Licenciada em Educação Física Universidade Estadual de Campinas-UNICAMP Departamento de Educação Física e Humanidades Campinas, São Paulo, Brasil g.giovannas@hotmail.com (ㄱ) http://orcid.org/0000-0002-2558-305X

Ademir De Marco

Doutor em Anatomia/Neuroanatomia Humana Universidade Estadual de Campinas-UNICAMP Departamento de Educação Física e Humanidades Campinas, São Paulo, Brasil demarco@fef.unicamp;br http://orcid.org/0000-0002-3562-3588 


\title{
The circus in early childhood education: experiences and artistic representations in drawing
}

\begin{abstract}
The circus has always maintained a close relation with the children's universe, stimulating magic, joy and dreams. This study analysed the children's understanding of the circus representations and appropriations, based on their own drawings about the circus activities. It consisted of a case study of 21 children aged between 4 and 5 years old, from a kindergarten institution. It was observed that before the proposal the external structure of the circus, the canvas, was the element most represented by the children, suggesting that although some children had never seen a circus spectacle before, they were already introduced to some of its physical structure. After 12 sessions of the pedagogical proposal, the canvas of the circus was no longer the most represented element, but also the protagonists, juggler and magicians. It was evidenced that the physical activities and dialogues have allowed the circus to be re-signified on Early Childhood Education.
\end{abstract}

KEYWORDS: Child rearing; Physical education; Circus; Design

\section{El circo en la educación infantil: experiencias y representaciones artísticas en el dibujo}

\section{RESUMEN}

El circo siempre mantuvo estrecha la relación con el universo infantil, despertando magia, alegría y sueños. Este estudio analizó representaciones y apropiaciones de los niños sobre el circo, a partir de sus propios dibujos, elaborados en una propuesta de actividades circenses. Consistió en un estudio de caso, con 21 niños de una institución de educación infantil, con edad entre 4 y 5 años. Se observó que antes de la propuesta la estructura externa del circo, la lona, fue el elemento más representado por los niños, sugiriendo este hecho, que aunque algunos niños nunca habían presenciado un espectaculo de circo, conocían su estructura física que en algún momento les fue presentada. Después de 12 sesiones de la propuesta pedagógica, la lona del circo dejó de ser el elemento más representado, surgiendo protagonistas, como el malabarista y el magico. Se evidenció que vivencias corporales y el diálogo permitieron resignificar el circo en la educación infantil.

PALABRAS-CLAVE: Educación infantil; Educación física; Circo; Dibujo 


\section{INTRODUÇÃO}

Os estudos sobre o circo no Brasil evoluíram significativamente, aglomerando um número cada vez maior de pesquisadores instigados com a temática. Ontañón, Duprat e Bortoleto (2012) destacam dois fatores que contribuíram para esse aumento: a maior divulgação dos espetáculos circenses pela mídia de massa, entre o final do século XX e o início do XXI; e pela constante procura, por parte dos professores, de conteúdos novos e atrativos para suas aulas. Esse fenômeno permitiu tanto o aprofundamento teórico da temática, quanto possibilitou que um número maior de pessoas vivenciasse a prática. O circo é uma manifestação cultural e artística, que cada vez mais tem sido tema nos âmbitos escolares.

Bortoleto, Pinheiro e Prodócimo (2011) demonstraram a relevância da arte circense no ambiente escolar, uma vez que se constitui como um importante patrimônio cultural.

Neste estudo o desenvolvimento do circo ocorreu na primeira etapa da educação enfantil, uma vez que este tema é amplamente representado na cultura infantil. Sendo este um nível sumariamente interdisciplinar na Educação Básica, os pesquisadores, professores de educação física, e professoras/pedagogas responsáveis pela turma assumiram a perspectiva de trabalho integrado.

Diferentemente dos demais níveis da Educação Básica, considera-se que educação infantil não deva ser estruturada no tradicional modelo, que se verifica nos demais, ou seja, com a fragmentação do conhecimento, por meio de diferentes disciplinas que são oferecidas. (AYOUB, 2005 , p. 144). Visto que na educação infantil, os objetivos indicam que as crianças, de zero a cinco anos, devem ter o máximo de vivências, visando ampliar o repertório social e cultural destas crianças, com enfoque na criatividade, expressão corporal e demais linguagens, conforme preconizado pela Base Nacional Comum Curricular - BNCC, BRASIL (2017). Assim, inferimos que a atuação de professores de educação física na educação infantil não deve se organizar de forma disciplinar ou apontar para uma perspectiva escolarizante. Em concordância com Silveira (2015, p.15), consideramos que professores de diferentes áreas possam "somar esforços na perspectiva da diversificação de propostas educativas a partir de diferentes olhares e formações". Visto que, é o cotidiano e a prática dos professores que definirão a fragmentação ou não dos conhecimentos. Espera-se que os mesmos sejam apresentados e desenvolvidos de forma integrada, por meio de estratégias interdisciplinares.

Neste sentido, vemos a temática do circo como grande aliada ao planejamento pedagógico. Os conteúdos circenses possibilitam diversificadas e ricas experiências que aliam os componentes 
cognitivo, emocional e motor, permitindo também estimular os aspectos sociais e evidenciar este importante aspecto da cultura infantil, representado pelo circo. Consequentemente, esta estratégia contribui com o desenvolvimento integral das crianças participantes em um programa desta natureza. A fim de ilustrarmos este pensamento, buscamos a citação em De Marco (2016);

Em minha opinião, o grande diferencial e a grande vantagem da educação infantil é que nela não há segmentação, ou seja, não se fala em disciplinas, mas sim em conteúdos e diretrizes que se baseiam nos jogos e brincadeiras. Há o que podemos denominar de predisposição pedagógica para se realizar um trabalho interdisciplinar que reúna todos os tipos de jogos e brincadeiras, incluindo aqui a música, a dança, a ginástica e as lutas. E por que não as artes circenses? Nesse ponto é que encontramos a intersecção da educação física com a educação infantil, com destaque para o fato de que o profissional de educação física mostra-se habilitado com todo o arsenal pedagógico para interagir com as crianças pequenas. (DE MARCO, 2016, p. 202).

Desta forma, o principal objetivo deste estudo foi analisar o processo de representações e apropriação das crianças sobre o circo, a partir de seus próprios desenhos elaborados, anteriormente e após, a realização de uma proposta de experiências corporais. Uma vez que influenciados pela mídia e pelo contexto, as crianças podem interiorizar significados distintos e/ou reduzidos sobre o circo.

O texto está estruturado em três momentos, no primeiro discorreremos sobre a utilização do desenho como linguagem e recurso metodológico. No segundo momento desvendaremos o ambiente do circo na escola, e na educação infantil.

No terceiro e último momento, faremos a análise da proposta pedagógica e dos desenhos realizados pelas crianças sobre o circo, no qual cada criança produziu dois desenhos em momentos distintos. A produção inicial ocorreu no primeiro instante da proposta pedagógica. A segunda produção foi realizada após a execução da proposta pedagógica que totalizou 12 sessões. Ambos os momentos de produção das representações artísticas foram propostos a partir dos seguintes ideais: “o que é circo, o que temos no circo, quem está no circo?”. Nesta análise procuramos responder às seguintes questões: 1) Quais indícios de compreensão sobre o circo podem ser observados nos desenhos das crianças?; 2) Quais são as possíveis contribuições da proposta pedagógica, realizada em conjunto com as professoras da turma, pesquisadores e crianças, para a construção, entendimento e o desenvolvimento das representações artísticas relacionados ao circo?

\section{A Utilização dos Desenhos Infantis}


Desde cedo, as crianças utilizam diversos tipos de linguagem para se comunicar com o mundo exterior. Nos primeiros anos de vida a linguagem corporal é preponderante para que estas se relacionem com o mundo e com os outros. Ao passo que se desenvolvem aprendem outros tipos de linguagens, como, a verbal, não verbal e escrita.

O uso dessas linguagens, segundo Vygostky (2007) permite que as crianças reflitam sobre o mundo exterior, e atribuam significados aos fenômenos e objetos que acercam. Desta forma, mais do que se comunicar, a linguagem permite que a partir do seu entendimento de mundo, as crianças se expressem e compartilhem suas experiências.

À medida que as crianças se inserem no universo cultural, elas são influenciadas e também influenciam o meio. Realizam as adaptações necessárias para fazerem parte do contexto e internalizam os elementos culturais que lhes são disponibilizados. Assim, os desenhos, mímicas, brincadeiras, gestos, sons, danças, movimentos, olhares ou palavras se constituem como linguagem que possibilitam que as crianças se expressem e registrem suas marcas no mundo (DOMINGUEZ; TRIVELATO, 2014).

Goldberg, Yunes e Freitas (2005) consideram o desenho infantil, em especial, como um dos aspectos mais importantes para o desenvolvimento, sendo um elemento mediador de conhecimento e autoconhecimento que permite organizar informações, processar experiências vividas e pensadas, e desenvolver um estilo de representação singular do mundo.

A imaginação e realidade cotidiana, mediadas pela linguagem, incorporam-se e são representadas pelo desenho daquilo que a criança conhece. Desta forma, os desenhos estão intimamente relacionados com as interações sociais.

Vygotsky (2009) afirma que as crianças não desenham aquilo que veem, mas sim o que sabem a respeito dos objetos. Representando seus pensamentos, seus conhecimentos e/ou suas interpretações sobre uma dada situação vivida ou imaginada. $\mathrm{O}$ autor também aponta que no desenvolvimento do desenho há um forte impacto da fala. Dessa forma, o desenho se constitui como uma linguagem gráfica permeada pela linguagem falada, portanto, para o autor;

As crianças pequenas dão nome a seus desenhos somente após completá-los; elas têm necessidade de vê-los antes de decidir o que eles são. À medida que as crianças se tornam mais velhas, elas adquirem a capacidade de decidir previamente o que vão desenhar. Esse deslocamento temporal do processo de nomeação significa uma mudança na função da fala. (VYGOTSKY, 2007, p.22)

Natividade, Coutinho E Zanella (2008) demonstram em seu trabalho a importância do desenho como procedimento de coleta de informações na pesquisa com crianças, assim como, as 
verbalizações destas sobre seus desenhos, uma vez que só elas compreendem completamente os sentidos e significados de suas produções. Ou seja, é necessário olhar para as elaborações das crianças pelas falas das próprias crianças.

Elali (2003) analisou o ambiente escolar sob o ponto de vista físico e suas relações com a natureza, a autora se valeu de estratégia denominada multimétodo, entre os diversos recursos metodológicos adotados, estava o desenho realizado pelas crianças da educação infantil, as quais representaram os vários espaços das escolas utilizados no cotidiano e, por meio de entrevistas puderam verbalizar os significados de suas representações. Temos aqui, portanto, mais um exemplo da importância do desenho como recurso de comunicação pela criança. De acordo com a autora;

A necessidade de uma troca mais ativa com o meio natural (sentar na areia, pegar em pequenos animais, molhar-se) surge de modo enfático no discurso e nos desenhos infantis, os quais sugerem que árvores, grama, água, areia e pequenos animais deveriam estar mais presentes no seu dia-a-dia. (ELALI, 2003, p. 315).

Fica evidenciado, por esta descrição que o desenho constitui um dos principais meios de representação da criança, quer sejam componentes de sua cultura ou elementos da natureza, a criança demonstra interesse e observação do mundo que a cerca, mostrando-se capaz de captar e reproduzir itens com os quais interage.

Os desenhos não devem ser analisados pela qualidade gráfica, tampouco apenas pelo olhar do adulto. Eles são utilizados pelas crianças com autonomia, e configuram um percurso lúdico, no qual a criança brinca com as cores, com os formatos, com os tamanhos... Por isso, os riscos e traçados infantis devem ser analisados pelos próprios autores. Além disso, quem sabe mais de suas produções do que eles mesmos? Nas análises também foi valorizado, todo o processo de produção, não só o resultado final.

Nosso interesse pelos desenhos e fala é o de compreender o processo de atribuição e apropriação de significados para o circo frente a uma proposta pedagógica. Como a partir da interação das crianças com elementos do circo por meio de brincadeiras, histórias, experiências de observações e materiais, elas se apropriam destas vivências e as representam em seus desenhos.

\section{O Circo na Escola}


Estudos recentes (Bortoleto e Silva 2017; Kronbauer e Nascimento, 2013; Ontañón T, Duprat, e Bortoleto, 2012) evidenciam o aumento da produção acadêmica sobre o circo na escola nos últimos anos, revelando seu potencial pedagógico e a valorização deste patrimônio cultural e artístico nos espaços educativos. O circo por onde passa espalha alegria, a grande variedade e possibilidade das artes circenses despertam o fascínio do público e de quem o pratica. Sendo um tema prazeroso e instigante que pode ser aplicado na escola.

Os diálogos do circo nos espaços escolares se manifestam de diferentes maneiras, sendo ainda mais forte na educação física Escolar. Caramês (2012) aponta as atividades circenses como uma possibilidade de aproximação com o lazer e o lúdico. Para Ontañón T. (2012) o circo, destacase como um conhecimento inovador, que oportuniza rica experiência corporal e estética. Takamori et al (2010) e Da Silva et al (2014) acentuam o desenvolvimento social, e a discussão de valores proporcionado pelo circo. Desta forma, estes e outros trabalhos já realizados, abordam a inclusão do circo na escola a partir de diferentes perspectivas, e em cada uma delas, fica justificada a importância e as contribuições do circo no contexto escolar.

Além disso, estes estudos demonstram a importância das brincadeiras mediadas pelas atividades circenses valorizando as ações lúdicas e espontâneas da criança. Em especial, na educação infantil em que o brincar é amplamente valorizado e entendido como essencial para o desenvolvimento das crianças pequenas. Neste nível da Educação Básica, as experiências vividas devem proporcionar o contato com variadas práticas culturais que motivem diferentes formas de expressão (GARANHANI, 2009). Assim, o reconhecimento do circo enquanto possível conteúdo, tendo em vista o aspecto lúdico e as possibilidades expressivas e imaginativas, possibilita o fazer pedagógico comprometido com a criança.

Silva e Martinelli (2016) propuseram o desenvolvimento da temática circense, em meio às experiências na educação infantil, em seu trabalho relatam a riqueza do circo enquanto constituinte de uma cultura própria, as possibilidades de experimentações diversas e a boa aceitação das crianças frente a este conteúdo.

Para o ensino de atividades embasadas no circo Duprat e Bortoleto (2007) propõem uma classificação, disposta em unidades didático-pedagógicas: Acrobacias (Aéreo, Solo e Trampolinismo), Manipulações de Objetos, Equilíbrios do Corpo (em Movimento, em Superfícies Instáveis) e Encenação (Expressão Corporal e Palhaço). Entretanto, para o desenvolvimento de um programa desta natureza nas escolas, os autores alertam que o objetivo central visa colocar o aluno em contato, em vivência com a cultura do circo, destacando que; 
O interesse pedagógico não está centralizado no domínio técnico dos conteúdos, mas sim no domínio conceitual deles, dentro de um espaço humano de convivência, no qual possam ser vivenciados aqueles valores humanos que aumentem os graus de confiança e de respeito entre os integrantes do grupo. (DUPRAT E BORTOLETO, 2007, p.176).

Outro ponto crucial para o desenvolvimento de atividades circenses na escola é o de identificar os conhecimentos já adquiridos antes de iniciar a proposta.

É de extrema importância identificar o conhecimento prévio de nossos alunos, identificando o que eles sabem sobre a arte do circo ou algum aspecto dela inerente, e possibilitar a eles que a compreensão desse fenômeno seja ampla e consistente, pois o que sabemos é que ela é muito sedutora. (DUPRAT E BORTOLETO, 2007, p. 187).

A maioria das crianças entra em contato com o universo do circo em algum momento de suas vidas, seja direta ou indiretamente, portanto, trata-se de uma realidade que possui uma estreita relação com a infância, em maior ou menor grau para cada criança.

Partindo destes pressupostos, é que avaliamos a possibilidade de inserir o tema do circo enquanto conteúdo pedagógico na educação infantil. Os movimentos corporais exigidos pelas diversas habilidades circenses colocam a criança diante de inúmeros e inovadores desafios para "se movimentar" corporalmente. Citando como exemplo, as atividades de malabares, sejam estas realizadas com retalhos de tules, bolas, pratos ou claves, requerem não apenas controle muscular, equilíbrio, coordenação apendicular e visomotora, como também avaliação cognitiva e adequado estado emocional durante o desenvolvimento das vivências.

Assim, é completamente plausível que as denominadas, unidades didático pedagógicas, possam ser simplificadas para a educação infantil, evidentemente que não serão exigidas habilidades complexas das crianças neste nível da Educação Básica, mas é perfeitamente plausível desenvolver um planejamento pedagógico exequível para a faixa etária de três a cincos de idade.

Como sabemos, a criança evolui de movimentos reflexos ao nascer, para os denominados movimentos voluntários, os quais implicam em intencionalidade e inserção social e cultural, portanto, falamos em movimento que tenham significado para a criança. Concordamos, portanto, que:

Quando uma criança se movimenta, ela o faz de forma contextual; o movimento realizado tem significado social e cultural para ela, cada criança aprende habilidades de seu meio e, para executar determinadas ações motoras, é preciso segurança emocional, é necessário que a criança sinta-se capaz de tal feito, caso contrário virá a dúvida, o fracasso e a consequente frustração. Em contrapartida, a 
execução de movimentos complexos, como os que requerem habilidades simultaneamente de ambas as mãos, como é o caso das performances com malabares, exige determinado nível cognitivo. A síntese desta descrição, ou seja, movimentos conscientes que integram um contexto social, que implicam em equilíbrio emocional e requerem participação de processos cognitivos, pode ser traduzida como motricidade. (DE MARCO, 2016, p. 194).

Resumindo, entendemos o circo enquanto uma manifestação cultural que pode estar inserida no contexto escolar, em especial na educação infantil, contribuindo significativamente para o desenvolvimento integral da criança, desde que respeitadas as características sociais e culturais do grupo de crianças com a qual estamos interagindo.

\section{MÉTODO}

O presente estudo, caracterizado como sendo de natureza qualitativa, seguiu o modelo "estudo de caso" (YIN, 2015) visou investigar um fenômeno sem desconsiderar a complexidade e multiplicidade de dimensões presentes no ambiente escolar em que estão inseridos os sujeitos participantes.

Este estudo fez parte de um projeto mãe denominado "CRI CRI - Espaço para a Criança Criar: Estudo pedagógico Interdisciplinar da Educação Infantil”, aprovado pelo Comitê de Ética em Pesquisa de uma universidade pública estadual, sob o parecer 937.801 na data 28 de dezembro de 2014, de acordo com as normas do CONEP. A pesquisa foi realizada em uma escola pública de educação infantil, localizada em um município do estado de São Paulo, onde 21 crianças, constituindo duas turmas, participaram do estudo. A turma dos Bichos composta por nove crianças de quatro a cinco anos de idade, e a turma do Livro composta por 12 crianças de três a quatro anos de idade.

A proposta fundamentada em atividades circenses ocorreu durante o primeiro e segundo semestres do ano letivo de 2017, com início no mês de maio. Ao final foram realizados 12 encontros, os quais ocorreram por meio de uma sessão semanal, com duração de aproximadamente uma hora no Espaço para a Criança Criar (Sala Cri Cri). Esta sala foi idealizada por meio de parceria firmada entre o Grupo de Estudo de Educação Física no Desenvolvimento Infantil GEEFIDI/FEF/UNICAMP com o Centro de Convivência Infantil CECI. De modo sucinto, o objetivo desta sala é o de proporcionar um espaço adequado e seguro para a movimentação corporal das crianças pequenas que frequentam a citada instituição de educação infantil.

Todas as atividades foram desenvolvidas pelo pesquisador, eventualmente com a participação de um integrante do GEEFIDI, e em conjunto com as professora(s) da turma. Em 
todas as sessões foram realizadas as seguintes etapas: roda de conversa inicial, vivências de atividades e roda de conversa final para a reflexão e discussão sobre as atividades desenvolvidas.

Antes e depois da proposta de atividades circenses as crianças foram convidadas a realizarem um desenho, individualmente, sobre a temática do circo a partir dos seguintes questionamentos “o que é circo, o que temos no circo e quem está no circo?". Junto ao pedido de desenho, solicitou-se aos mesmos que descrevessem, por meio da fala, o que haviam representado.

\section{RESULTADOS E DISCUSSÃO}

\section{A Proposta de Atividades Circenses}

A proposta foi norteada pela classificação de Duprat e Bortoleto (2007), sempre de modo lúdico com brincadeiras e atividades incentivadoras, sendo considerado o conhecimento prévio das crianças. Além disso, todos os momentos continham uma história simples, mas que fosse suficientemente atrativa para o arrebatamento e imersão das crianças nas atividades. A seguir relataremos de modo sucinto e destacaremos os principais aspectos das vivências com os temas: Encenação, Malabarismo, e Equilibrismo.

\section{- Encenação (Expressão Corporal)}

Na temática de Expressão Corporal foram propostas atividades com a intenção explícita na expressão e comunicação por meio dos gestos, ritmos, sons e música. Em um primeiro momento, as crianças tiveram a oportunidade de imitar gestos e movimentos tipicamente utilizados pelos protagonistas circenses, com objetivo de ampliar o repertório dos mesmos. Em seguida, foram priorizadas as atividades em que as crianças pudessem construir seus próprios gestos e movimentos. Nosso enfoque se constituiu na busca de olhar sensível à expressão corporal como linguagem que permite a expressão de ideias, emoções e estados afetivos. Desta forma, utilizamos jogos e brincadeiras que envolveram a interpretação e expressão de dimensões cênicas, aproximando-se da atuação do palhaço circense, mímico e mágico.

Nas vivências ficou evidenciada a ampla capacidade de comunicação das crianças, a interação entre todos se mostrou eficaz, e na aparente desordem do grupo, havia ordem nas ações das crianças. 
$\mathrm{Na}$ temática de malabares foram propostas atividades ou situações lúdicas que exigiram a manipulação de objetos, como fundamento básico. Foram utilizados diferentes materiais, como tules, bolas, bexigas e prato chinês. Nas vivências as crianças foram desafiadas a explorar os materiais com diferentes segmentos corporais, uma vez que no início da atividade utilizavam apenas uma das mãos. Especificamente, com os tules e bexigas, as atividades de lançamento possibilitaram maior assimilação pelas crianças, tendo em vista a lenta velocidade de queda dos objetos, estimulando assim a motivação para tentativas mais desafiadoras, como lançamentos de duas bexigas ao mesmo tempo ou lançamentos em parcerias.

Em outro momento, as crianças puderam socializar com os colegas suas descobertas e aprendizados, permitindo animada troca de conhecimento entre os próprios alunos. Este momento foi muito interessante, porque os desafios não surgiam dos professores, e sim, dos seus próprios colegas. Com isto ficou visível o contentamento dos pequenos quando tinham a oportunidade de "ensinar" o que tinham vivenciado.

Outro aspecto relevante que pode ser observado nas sessões, foi à preferência dos meninos pelos tules das cores azul e preta, e das meninas pelas escolhas dos tules amarelos e rosa. Durante a atividade e na roda de conversa final, dialogamos com as crianças na tentativa de desmistificar tal divisão estereotipada das cores, a partir da questão de gênero que começava a ser evidenciada pelo grupo de crianças.

\section{- Acrobacias (Solo e Aéreo)}

$\mathrm{Na}$ temática de acrobacias as criações corporais foram construídas por intermédio de mimetismos inspirados em animais, objetos, desenhos, sons e palavras. Nas vivências as crianças tiveram a oportunidade de fazerem "piruetas", saltar, pular, rolar, escorregar, enfim, imaginar e brincar com o seu próprio corpo.

Destacamos nesse ponto, como a Sala Cri Cri contribuiu para o desenvolvimento das atividades de acrobacias o espaço incentivava e oferecia segurança para a movimentação corporal para as crianças, uma vez que possuía tatames, colchões e espumados de diferentes densidades e formatos.

Além das acrobacias no solo, tivemos a oportunidade de apresentar às crianças o tecido acrobático. Desta forma, elas puderam vivenciar e experimentar poses acrobáticas básicas na "trança". Foi uma atividade diferenciada, em virtude da proposta solicitar, além da consciência corporal, o respeito pelo colega e a cooperação, pois mesmo apresentando atividades paralelas foi necessário aguardar a vez para utilizar o tecido. 
- Equilibrismo (Superfícies Instáveis)

Na temática de equilibrismo, foram realizadas atividades ou situações lúdicas que exigiram equilíbrio do corpo em superfícies instáveis. Priorizamos tanto o ato motor, como a criação de vínculos de confiança nos professores, nos colegas e em si mesmo, além da autossuperação nas vivências.

Um dos recursos utilizados nas atividades que priorizaram o equilíbrio dinâmico foi o equipamento slackline, o qual simulou a "corda bamba”. É importante pontuar que todas as medidas de segurança foram adotadas, para que as atividades apresentassem riscos mínimos para as crianças. Foram elaboradas alternativas que despertassem a fantasia e "o faz de conta" para a construção de cenários elaborados pelas crianças, nos quais elas pudessem se imaginar em outros ambientes, como "atravessar sobre uma corda bamba que está muito longe do chão", ou mesmo "passar sobre uma ponte em que o rio está cheio de tubarões".

Desta forma, todas as crianças realizaram a atividade com auxílio dos professores com todo o cuidado necessário. Durante a roda de conversa final elas demonstraram estar muito contentes com o que realizaram, mas tristes por já ser o momento de finalizar as brincadeiras.

Os temas foram escolhidos com a pertinência dos materiais e do espaço disponível na instituição. Acentuamos que o diálogo e o debate foram elementos fundamentais que permitiram que as crianças expressassem suas opiniões, sentimentos e emoções ao longo da proposta.

\section{Os Desenhos antes da Proposta}

Antes de iniciarmos a reflexão sobre os desenhos, é importante ressaltar que embora as turmas tenham diferença de idade, as crianças menores trouxeram tantos elementos circenses quanto as maiores, aparentando uma situação prévia de conhecimento semelhante sobre o circo. Ambas realizaram a mesma intervenção pedagógica, e por isso, neste caso não faremos distinção de turmas.

Dentre os 21 desenhos realizados inicialmente, 17 realizaram uma ou mais representações externas ou internas do circo e quatro desenhos não demonstraram nenhuma relação possível com o circo. As falas das crianças sobre os desenhos, registradas no diário de campo possibilitaram melhor classificação dos mesmos. 
Em meio aos 17 desenhos que trouxeram aspectos do circo, o elemento mais representado foi o da lona, a qual esteve presente em 10 desenhos. O palhaço é o segundo elemento mais representado (5), seguida dos equilibrista (2), animais (2), malabaristas (1) e mágico (1).

A quantidade de representações externas do circo foi extremamente significativa. As crianças destacaram a lona e tenda de circo como sendo colorida, grande e um local onde as pessoas são muito felizes. Deixando de evidenciar aspectos internos como espetáculos, apresentações e artistas do circo. Podemos inferir sobre este fato, que embora algumas crianças nunca tivessem presenciado um espetáculo de circo, ainda assim elas conheciam sua estrutura física externa, a qual muito provavelmente lhes foi apresentada em algum momento.

Outro ponto importante identificado foi o da presença de animais nos desenhos. Quando indagadas, as crianças afirmavam que havia leões, elefantes e até girafas no circo. No decorrer da proposta, tomamos muito cuidado com este tema, isto porque não queríamos apresentar nossa opinião logo de início, e sim fazer com que eles refletissem sobre o assunto. Pouco a pouco, debatíamos sobre a presença dos animais no circo, assim como, o real lugar de pertencimento dos bichinhos.

E como já era de se esperar o palhaço um dos itens mais representados, isso porque ele é dentre os demais elementos circenses, o que mais tem espaço na mídia infantil, quando comparado ao mágico, malabaristas e equilibristas. Os palhaços são personagens centrais de programas e desenhos infantis apresentados na televisão, nas festas e eventos para crianças, em eventos escolares, em peças teatrais infantis, em parques de diversão, entre tantas outras situações que poderiam ser citadas.

Quanto aos outros elementos, ficamos surpresos com a aparição dos mágicos, malabaristas e equilibristas, algo que não era esperado por nós no primeiro momento da pesquisa. Mas, ficamos mais surpresos ainda quando as crianças que os representaram os descreveram de forma precisa e fiel. Contudo foi um número pequeno de representações, fato este que nos sugere que estas atrações devam ser mais exploradas em futuras intervenções com esta proposta pedagógica. Na categoria elementos diversos foram dispostos os itens que de alguma forma se aproximam do circo, como a pipoca e a montanha russa.

\section{Os desenhos depois da proposta}


Ao final da realização da proposta, todas as crianças trouxeram novos elementos circenses aos seus desenhos. Neste momento dentre os 21 desenhos, algumas crianças inclusive apontaram dois ou três elementos em sua produção, fato que não ocorreu no primeiro momento.

$\mathrm{Na}$ segunda produção o elemento que teve a maior frequência foi o malabarista, presente em 15 dos 17 desenhos realizados. O equilibrista (7) é o segundo elemento mais representado, seguido do mágico (6), do palhaço (5), elementos diversos (2), lona (1) e acrobata (1).

A lona de circo passou a ser menos representada, já sendo esperado, uma vez que a proposta pedagógica abrangeu outros elementos circenses. As crianças deixaram de representar um elemento externo para representar os elementos internos que foram explorados, pedagogicamente, na proposta.

Os protagonistas dos circos representados pelas crianças, contam com a presença de "objetos chave", ou seja, os mágicos foram representados com sua cartola e varinha, os malabaristas com bolas, bexigas e pratos, tais objetos caracterizam os protagonistas retratados. Representar a cartola na cabeça de um 'boneco' faz com que ele deixe de ser comum e se torne um mágico, bem como traçar uma linha abaixo de seus pés o transforma em equilibrista. Esses "objetos chave" demonstram uma espécie de ativadores dos artistas do circo que somados a imaginação e ludicidade das crianças dão vida e ação aos protagonistas ilustrados.

Já os animais não apareceram em nenhum desenho da segunda produção. Esta constatação nos sugere que o diálogo e as discussões sobre o tema durante a realização da proposta, tiveram alguma repercussão na significação do lugar dos bichinhos. Os elementos diversos continuam sendo retratados e isso não quer dizer que não se aproximem do circo, mas apenas que não se encaixam em nenhuma outra categoria de análise do estudo.

Parece-nos evidente que a proposta pedagógica tem potencial para influenciar os desenhos finais, assim como, toda a prática pedagógica de um professor tem potencial para influenciar o modo como uma criança irá enxergar e compreender o mundo. Por isso, a necessidade de se pensar, planejar e refletir sobre toda ação no ambiente escolar. Como propor, o que propor, e quando propor, são perguntas que todo docente deve se fazer constantemente, pois as experiências vividas na infância podem ser decisivas para o desenvolvimento das crianças.

$\mathrm{Na}$ sequência selecionamos as produções de três crianças produzidas antes e após a finalização da proposta pedagógica, com o intuito de ilustrar a experiência vivida. Consideramos como critério para a escolha das produções abaixo, os desenhos das crianças que tiveram frequência maior que $70 \%$ nas atividades realizadas.

\section{As produções de Luca}


Reproduzimos, nas figuras 3 e 4, os desenhos produzidos por Luca antes e após a proposta, respectivamente.

Figura 3. Representação Inicial do Circo produzida por Luca.

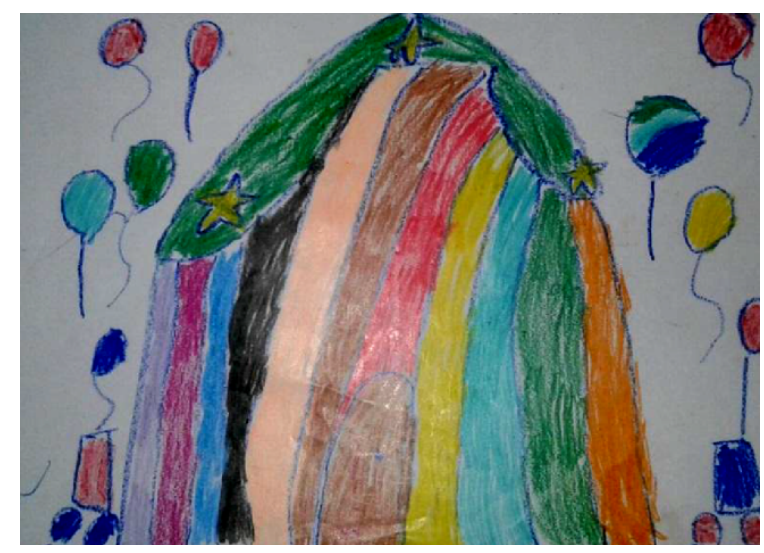

Fonte: Dados da Pesquisa.

Figura 4. Representação Final do Circo Produzida por Luca

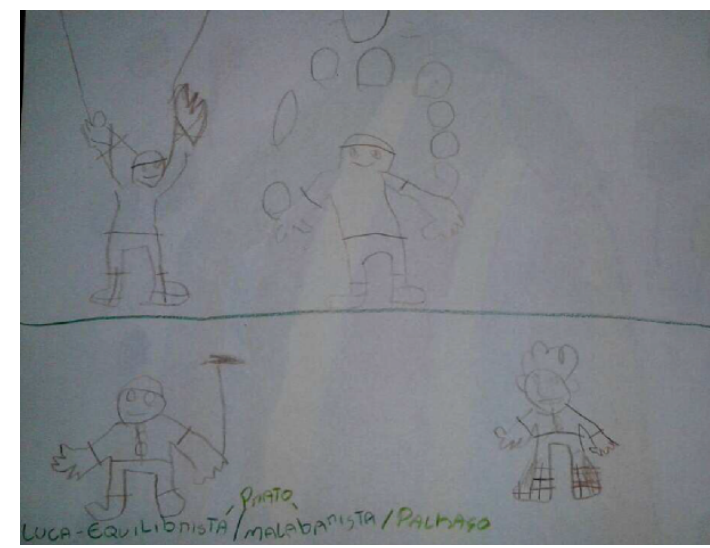

Fonte: Dados da Pesquisa

$\mathrm{Na}$ primeira produção Luca desenhou a tenda do circo utilizando muitas cores, também representou bexigas e pessoas que estavam indo assistir ao espetáculo de circo. Já na segunda produção representou dois malabaristas um com bolas e outro com o prato, um palhaço e um equilibrista. Sendo que desta vez Luca não quis colorir o desenho.

\section{As produções de Igor}

Reproduzimos, nas figuras 5 e 6, os desenhos produzidos por Igor antes e após a proposta, respectivamente. 
Figura 5. Representação Inicial do Circo produzida por Igor

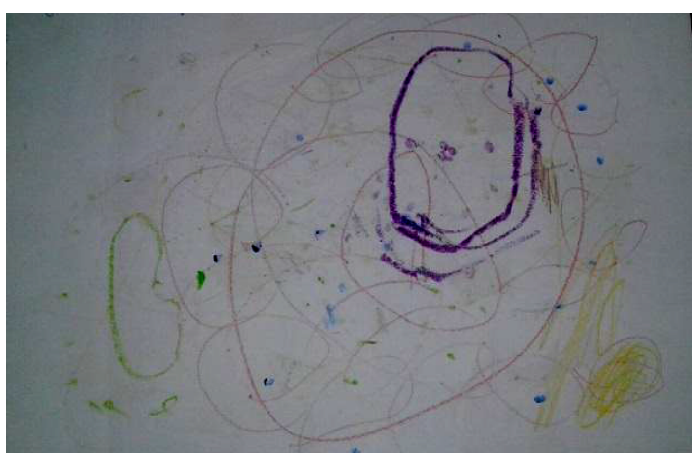

Fonte: Dados da Pesquisa

Figura 6. Representação Final do Circo produzida por Igor.

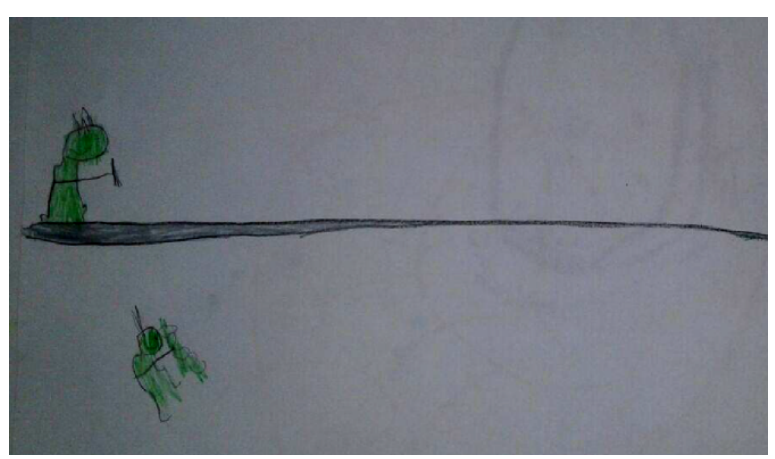

Fonte: Dados da Pesquisa

Na primeira produção Igor desenhou o motoqueiro que estava indo para o circo, e as linhas circulares mostram o caminho percorrido. Na segunda produção, Igor desenhou um equilibrista sobre a corda bamba, e abaixo um malabarista com bolinhas.

\section{As produções de Clara}

Reproduzimos, nas figuras 7 e 8 , os desenhos produzidos por Clara antes e após a proposta, respectivamente.

Figura 7. Representação Inicial do Circo produzida por Clara. 


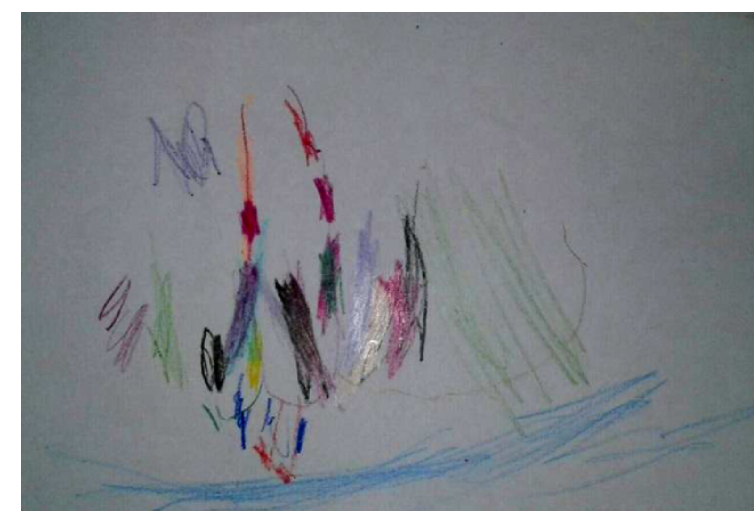

Fonte: Dados da Pesquisa

Figura 8. Representação Final de Clara.

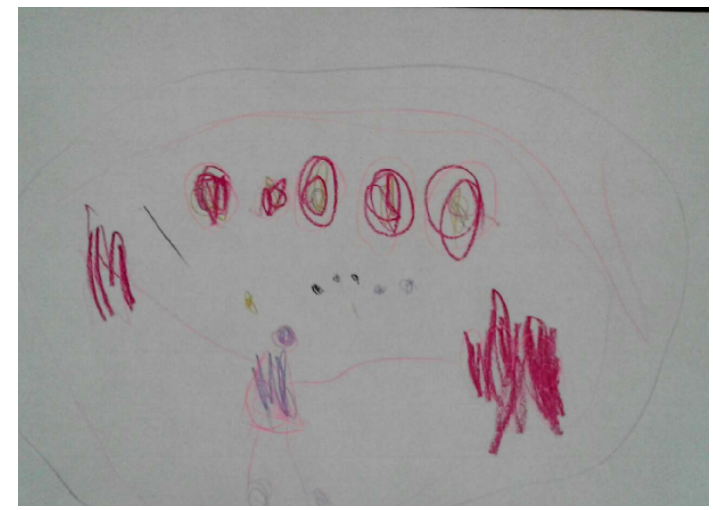

Fonte: Dados da Pesquisa

Na primeira produção Clara desenhou a tenda do circo e utilizou lápis de várias cores. A segunda produção se tornou mais nítida, Clara desenhou uma malabarista com suas bolinhas. Duas bolinhas estavam nas mãos da malabarista e as outras no ar, segundo ela, a artista estava se apresentando.

Nestas, e nas outras produções que aqui não foram exemplificadas, evidenciou-se a ampliação do repertório sobre o circo em seus desenhos. As turmas demonstram ter compreendido os elementos circenses apresentados pela proposta. Além disso, como pode ser observado, a fala das crianças sobre suas próprias produção se tornam importantes na medida em que nós, enquanto adultos, não conseguimos por meio das representações gráficas, interpretar o que a criança quis expressar.

Destaca-se ainda que, nessas e em outras produções, assim como nos desenhos de Igor e Clara, a preferência das crianças em colorir com o domínio das cores verde e rosa, respectivamente. Com isto, podemos perceber que, apesar da nossa proposta, o estudo ainda indica a predominância de estereótipos, como o de gênero, por exemplo, no uso das cores. A desconstrução destas 
representações é um longo caminho a se percorrer, para que possamos eliminar ou reduzir concepções historicamente impostas para os papéis masculinos e femininos.

\section{CONSIDERAÇÕES FINAIS}

O estudo demonstra que uma proposta baseada nas vivências corporais e no diálogo permite, na educação infantil, a apropriação de temas como o circo. A partir das novas produções artísticas é possível identificar novas repercussões na percepção e significação dos elementos circenses, influenciados pela proposta pedagógica realizada em conjunto com as crianças.

Cabe destacar que a inserção das atividades circenses na educação infantil representa uma possibilidade de variada gama de experiências relacionadas ao movimento, a cultura e aos valores que contribuem para o desenvolvimento integral das crianças que frequentam este nível da Educação Básica.

As produções artísticas se constituíram como importante instrumento que possibilitou elencar grande número de informações sobre as concepções das crianças e ter acesso aos significados atribuídos à sua produção e, consequentemente, à compreensão de suas ideias sobre a temática.

Sobre a inserção do professor de educação física na educação infantil, ocorreu uma efetiva integração com as professoras da turma. As mesmas se envolveram com o desenvolvimento da proposta e do estudo, contribuindo com conhecimentos e auxiliando no decorrer das atividades, possibilitando assim o estabelecimento de parceria entre os professores de educação física e as pedagogas. Configurando, portanto, ações pedagógicas interdisciplinares entre estas duas áreas do conhecimento humano, a Pedagogia e a educação física. Além é claro, da possibilidade de práticas que integrem professores de outras áreas que estejam inseridos neste nível da Educação Básica.

\section{REFERÊNCIAS}

AYOUB, Eliana. Reflexões sobre a educação física na educação infantil. Revista Paulista de Educação Física, 2001.

BRASIL. Ministério da Educação. Base nacional comum curricular. Brasília, DF: MEC, 2017. Disponível em: http://basenacionalcomum.mec.gov.br/download-da-bncc/. Acesso em: 13 de abril de 2018.

BORTOLETO, Marco. Antonio. Coelho; PINHEIRO, Pedro Henrique Godoy Gandia; 
PRODÓCIMO, Elaine. Jogando com o circo. São Paulo: Fontoura, 2011.

BORTOLETO, Marco Antonio Coelho; SILVA, Erminia. Circo: Educando entre as gretas. Rascunhos, v.4 n.2, p.104-117, 2017.

CARAMÊS, Aline Souza; KRUG, Hugo Norberto; TELLES, Cassiano; DA SILVA, Daiane Oliveira. Atividades circenses no âmbito escolar enquanto manifestação de ludicidade e lazer. Motrivivência, v.14 n.39, p. 177-185, 2012.

DA SILVA, Daiane Oliveira et al. O circo na escola: um relato de experiência dos professores. Revista Didática Sistêmica, v. 16, n. 2, p. 84-92, 2014.

DE MARCO, Ademir. Circo, desenvolvimento e educação infantil. In: BORTOLETO, Marco. Antonio. Coelho; ONTAÑÓN BARRAGAN, Teresa; SILVA, Ermínia. Circo: horizontes educativos. Campinas: Autores Associados, 2016.

DOMINGUEZ, Celi Rodrigues Chaves; TRIVELATO, Silvia Luiza Frateschi. Young children in the expressing meaning about butterflies: how do they use languages. Ciênc. educ. (Bauru), Bauru, v. 20, n. 3, p. 687-702, Sept. 2014.

DUPRAT, Rodrigo Mallet; BORTOLETO, Marco Antonio. Coelho. Educação Física escolar: pedagogia e didática das atividades circenses. Revista Brasileira de Ciências do Esporte, v. 28, n. $2,2007$.

ELALI, Gleice Azambuja. O ambiente da escola - o ambiente na escola: uma discussão sobre a relação escola-natureza em educação infantil. Estudos de Psicologia, v. 8, n. 2, p. 309-319, 2003.

GARANHANI, Marynelma Camargo. A Educação Física na Educação Infantil: uma proposta em construção. In: FILHO, Nelson. Figueiredo. Andrade.; SCHNEIDER, Omar. Educação Física para a Educação Infantil: conhecimento e especificidade. Sergipe: Editora da UFSE, 2009.

GOLDBERG, Luciane Germano; YUNES, Maria Angela Mattar; FREITAS, José Vicente. O desenho infantil na ótica da ecologia do desenvolvimento humano. Psicologia em Estudo, Maringá, v. 10, n. 1, p. 97-106, 2005.

KRONBAUER, Gláucia Andreza; NASCIMENTO, Maria Isabel Moura. O circo e suas miragens: A Escola Nacional do Circo e a história dos espetáculos na produção acadêmica brasileira. Revista HISTEDBR On-Line, v. 13, n. 52, p. 238-249, 2013.

NATIVIDADE, Michelle Regina; COUTINHO, Maria Chalfin; ZANELLA, Andréa Vieira. Children's drawing in research: a historical-cultural analysis. Contextos Clínic, São Leopoldo, v. 1, n. 1, p. 9-18, 2008.

ONTAÑÓN, Teresa. Atividades circenses na educação física escolar: Equilíbrios e desequilíbrios pedagógicos. (Dissertação de Mestrado). Universidade Estadual de Campinas, Campinas, 2012.

ONTAÑÓN, Teresa; DUPRAT, Rodrigo. Mallet; BORTOLETO, Marco. Antonio. Coelho.

Educação física e atividades circenses: "O estado da arte". Movimento, v. 18 n. 2, p.149-168, 2012. 
SILVA, Lisandra Oliveira; MARTINELLI, Rafael. O circo itinerante: compartilhando experiências de estágio de educação física na educação infantil. Cadernos de Formação RBCE, v. 7, n. 2, 2017.

SILVEIRA, Juliano. Reflexões sobre a presença da Educação Física na primeira etapa da educação básica. Motrivivência, v. 27, n. 45, p. 13-27, 2015.

TAKAMORI, Flora Sumie; BORTOLETO, Marco Antonio Coelho; LIPORONI, Maikon Oliveira; PALMEN, Mario Johannes Henricus; DI CAVALLOTTI, Thais. Abrindo as portas para as atividades circenses na Educação Física escolar: um relato de experiência. Pensar a Prática, v. 13, n. $1,2010$.

VYGOTSKY, Lev Semyonovich. Pensamento e linguagem. São Paulo: Martins Fontes, 2009.

VYGOTSKY, Lev Semyonovich. A formação social da mente. São Paulo: Martins Fontes, 2007.

YIN, Robert K. Estudo de Caso-: Planejamento e Métodos. Bookman editora, 2015.

\section{NOTAS DE AUTOR}

\section{AGRADECIMENTOS}

Os autores deste trabalho agradecem às instituições e participantes da pesquisa.

CONTRIBUIÇÃO DE AUTORIA - Não se aplica.

\section{FINANCIAMENTO}

Agradecemos a CAPES pelo apoio financeiro do Programa Novos Talentos para o projeto "Intervenções Pedagógicas da UNICAMP na Educação Básica de Campinas e Região" nº 66446.

CONSENTIMENTO DE USO DE IMAGEM - Não se aplica.

\section{APROVAÇÃO DE COMITÊ DE ÉTICA EM PESQUISA}

O estudo foi aprovado em 28 de dezembro de 2014, pelo Comitê de Ética em Pesquisa da Faculdade de Ciências Médicas da UNICAMP com o parecer $n^{\circ} 937.801$.

\section{CONFLITO DE INTERESSES}

Os autores do manuscrito declaram a inexistência de conflito de interesses em relação ao presente artigo

\section{LICENCAA DE USO}

Os autores cedem à Motrivivência - ISSN 2175-8042 os direitos exclusivos de primeira publicação, com o trabalho simultaneamente licenciado sob a Licença Creative Commons Attribution Non-Comercial ShareAlike (CC BY-NC SA) 4.0 International. Estra licença permite que terceiros remixem, adaptem e criem a partir do trabalho publicado, desde que para fins não comerciais, atribuindo o devido crédito de autoria e publicação inicial neste periódico desde que adotem a mesma licença, compartilhar igual. Os autores têm autorização para assumir contratos adicionais separadamente, para distribuição não exclusiva da versão do trabalho publicada neste periódico (ex.: publicar em repositório institucional, em site pessoal, publicar uma tradução, ou como capítulo de livro), com reconhecimento de autoria e publicação inicial neste periódico, desde que para fins não comerciais e compartilhar com a mesma licença. 


\section{PUBLISHER}

Universidade Federal de Santa Catarina. Programa de Pós-Graduação em Educação Física. LaboMídia - Laboratório e Observatório da Mídia Esportiva. Publicado no Portal de Periódicos UFSC. As ideias expressadas neste artigo são de responsabilidade de seus autores, não representando, necessariamente, a opinião dos editores ou da universidade.

\section{EDITORES}

Mauricio Roberto da Silva, Giovani De Lorenzi Pires, Rogério Santos Pereira.

\section{HISTÓRICO}

Recebido em: 08 de novembro de 2018.

Aprovado em: 01 de março de 2019. 